Article

\title{
Heat Transfer Enhancement of Plate-Fin Heat Sinks with Different Types of Winglet Vortex Generators
}

\author{
Jin-Cherng Shyu * (1) and Jhao-Siang Jheng \\ Department of Mechanical Engineering, National Kaohsiung University of Science and Technology, \\ Kaohsiung 80778, Taiwan; jheng840210@gmail.com \\ * Correspondence: jcshyu@nkust.edu.tw or jcshyu1207@hotmail.com; Tel.: +886-7-3814526 (ext. 15343)
}

Received: 14 July 2020; Accepted: 5 October 2020; Published: 7 October 2020

\begin{abstract}
Because the delta winglet in common-flow-down configuration has been recognized as an excellent type of vortex generators (VGs), this study aims to experimentally and numerically investigate the thermo-hydraulic performance of four different forms of winglet VGs featuring sweptback delta winglets in the channel flow in the range $200<R e<1000$. Both Nusselt number and friction factor of plate-fin heat sinks having different forms of winglets, including delta winglet pair (DWP), rectangular winglet pair (RWP), swept delta winglet pair (SDWP), and swept trapezoid winglet pair (STWP), were measured in a standard wind tunnel without bypass in this study. Four rows of winglets with in-line arrangement were punched on each 10-mm-long, 0.2-mm-thick copper plate, and a total of 16 pieces of copper plates with spacing of $2 \mathrm{~mm}$ were fastened together to achieve the heat sink. The projected area, longitudinal and winglet tip spacing, height and angle of attack of those winglets were fixed. Besides that, three-dimensional numerical simulation was also performed in order to investigate the temperature and fluid flow over the plate-fin. The results showed that the longitudinal, common-flow-down vortices generated by the VGs augmented the heat transfer and pressure drop of the heat sink. At airflow velocity of $5 \mathrm{~m} / \mathrm{s}$, the heat transfer coefficient and pressure drop of plain plate-fin heat sink were $50.8 \mathrm{~W} / \mathrm{m}^{2} \cdot \mathrm{K}$ and $18 \mathrm{~Pa}$, respectively, while the heat transfer coefficient and the pressure drop of heat sink having SDWP were $70.4 \mathrm{~W} / \mathrm{m}^{2} \cdot \mathrm{K}$ and $36 \mathrm{~Pa}$, respectively. It was found that SDWP produced the highest thermal enhancement factor (TEF) of 1.28 at $R e=1000$, followed by both RWP and STWP of similar TEF in the range $200<R e<1000$. The TEF of DWP was the lowest and it was rapidly increased with the increase of airflow velocity.
\end{abstract}

Keywords: plate-fin; winglet; Nusselt number; friction factor; thermal enhancement factor

\section{Introduction}

Power electronics such as thyristor, GTO, IGCT, power BJT, power MOSFET, and IGBT that are responsible for controlling and converting electrical power in the system have become widely used in response to the urgent demand of reducing the worldwide greenhouse gas emissions to retard the global warming. The application of power electronics related to the reduction of greenhouse gas emission includes integration of renewable resources into the power grid and the driving of motors for electric or hybrid electric vehicles, and so on.

As the function of power electronics become powerful, and in the meantime the die size steadily shrinks, the amount of heat and heat flux to be dissipated at limited junction temperatures to avoid failure is continuously increasing. Therefore, effective thermal management is a key for reliable operation of power electronics [1-6]. Cooling methods can be classified into two categories according to the medium used to dissipate the heat. One is air cooling, and the other is liquid cooling using water or dielectric fluid as working fluid. It is a cost effective way to cool the electronic devices using ambient fluid by attaching a forced air cooled heat sink to the casing of the electronic chip. However, the thermal 
resistance of such architecture could be fairly high, because of the low heat transfer coefficient between fin array and air, leading to the demand of heat transfer enhancement of air cooling. Accordingly, numerous methods to enhance heat transfer of an air-cooled heat sink have been proposed. Wang [7] provided a detailed review on those techniques that are applicable to the forced air-cooled heat sink used to cool the electronic devices.

Among those approaches, installing VGs on the fin surface has become one of the commonly used approaches since an early work [8]. A VG is responsible for producing vortices as the fluid flows over it, for the induced vortices enhance heat transfer rate on a flat surface [9]. The numerical study showed that a delta wing protruding from the base surface of a rectangular channel at an angle of attack of $26^{\circ}$ caused a $34 \%$ increase in the spanwise average Nusselt number at the channel exit, compared to that of a plain plate [10]. Tiggelbeck et al. [11] experimentally investigated the heat transfer and drag caused by two rows of delta winglet pairs in either aligned or staggered arrangement in a channel at Reynolds number higher than 2000. They found that the heat transfer enhancement was $80 \%$ at $R e=6000$ on a channel wall with an area of 37.5 times the winglet area in an aligned arrangement. However, both studies $[10,11]$ indicated that one of the expenses of using VGs is the increase in pressure drop because of various recirculation zones behind the trailing edge of the VGs, and the increase in the friction factor is greater at higher Reynolds numbers. Four basic forms of VGs, including delta wing, rectangular wing, delta winglet pair, and rectangular winglet pair, were experimentally tested in the Reynolds number range between 2000 and 9000 and for angles of attack between $30^{\circ}$ and $90^{\circ}$ [12]. Results show that winglets perform better than wings and the delta winglet pair can enhance heat transfer by $46 \%$ at $R e=2000$ to $120 \%$ at $R e=8000$ at an angle of attack of $65^{\circ}$ over the heat transfer on a plate. Biswas et al. found [13] that the angle of attack of the winglet VGs that produced longitudinal vortices in a laminar flow obviously affected the heat transfer enhancement and the pressure drop, and delta winglet type VG showed great promise for enhancing the heat transfer in plate-fin heat exchangers. The numerical simulation [14] on the longitudinal winglet VGs of different shape, geometric sizes, and locations shows that, with the same area of VGs, delta winglet pair is more effective than rectangular winglet pair on heat transfer enhancement in the channel at Reynolds numbers between 800 and 3200. In addition, with the increase in the distance between the inlet and the winglets, the overall Nusselt number was decreased while the total pressure drop was unchanged. With the increase of VG area, both Nusselt number and pressure drop were increased. Tian et al. [15] found that delta winglet pair (DWP) in common flow-down configuration was the most efficient versus DWP in common flow-up, and rectangular winglet pair (RWP) in both common flow-down and common flow-up configurations. An experimental work [16] shows that the influence of counter rotating vortices downstream may enhance the overall Nusselt number of the system and thereby increase the heat transfer rate. An increment in Nusselt number by $20 \%$ was reported for the longitudinal VGs on the fin surface. Different from the aforementioned results, a greater heat transfer enhancement with rectangular winglets was reported, compared with that of the delta winglets at Reynolds numbers between 450 and 3000 [17]. The numerical results reported by Oneissi et al. [18] showed that an innovative VG configuration, inclined projected winglet pair (IPWP) exhibited a superior thermal enhancement factor of IPWP to DWP, especially in the range of moderate Reynolds number between 4600 and 10,800. Over the past few years, studies focusing on the curvy winglet effect on the thermo-hydraulic performance have also been performed [19-23]. However, the cost of fabrication of curvy winglets could be a major concern.

Based on a literature survey, it has been reported that the heat transfer and pressure drop would be increased simultaneously due to the installation of VGs on a flat surface, and numerous factors of VGs affect the performance. Besides that, the delta winglet in common-flow-down configuration is commonly recognized as an excellent type of VGs [10-15] at medium or high Reynolds numbers. Therefore, this study aimed to experimentally and numerically investigate the thermo-hydraulic performance of four different forms of winglets featuring sweptback delta winglets in the channel flow with Reynolds number less than 1000. The friction factor, Nusselt number, and the thermal 
enhancement factor of those winglets will be examined, and the sweptback effect on the heat transfer and fluid flow will be discussed as well.

\section{Experimental Setup}

In order to measure the heat transfer performance of the heat sinks and the pressure drop of the air across the heat sinks, an open wind tunnel shown in Figure 1 was established based on ASHRAE wind tunnel standard (ASHRAE 41.2-1987). The ambient air was forced to cross the test section of the wind tunnel by a centrifugal fan with an inverter installed at the outlet of the wind tunnel. To avoid and minimize the effect of flow maldistribution in the experiments, both an air straightener-equalizer and a mixer were provided before the test section. The inlet and the exit temperatures across the test heat sink were measured by two T-type thermocouple meshes. The former consists of four thermocouples while the latter contains 16 thermocouples. The sensor locations inside the rectangular duct were established following ASHRAE recommendation [24]. During the isothermal test, the variation of these thermocouples was within $0.2^{\circ} \mathrm{C}$. In addition, all the thermocouples were pre-calibrated by a quartz thermometer having $0.01{ }^{\circ} \mathrm{C}$ precision, so that the accuracies of the calibrated thermocouples were of $0.1^{\circ} \mathrm{C}$. The pressure drop of the airflow across the tested heat sink was measured by a differential pressure transducer (YOKOGAWA EJA120A-M), while the other differential pressure transducer (YOKOGAWA EJA110A-L) was used to detect the airflow pressure drop across a multiple nozzle code tester designed according to ASHRAE 41.2 standard [25] to determine the air flow rate through the wind tunnel. All data signals generated by both thermocouples and differential pressure transducers were collected and converted by a data acquisition recorder (YOKOGAWA MX-100). The data acquisition recorder then transmitted the converted signals through Ethernet interface to the host computer for further operation.

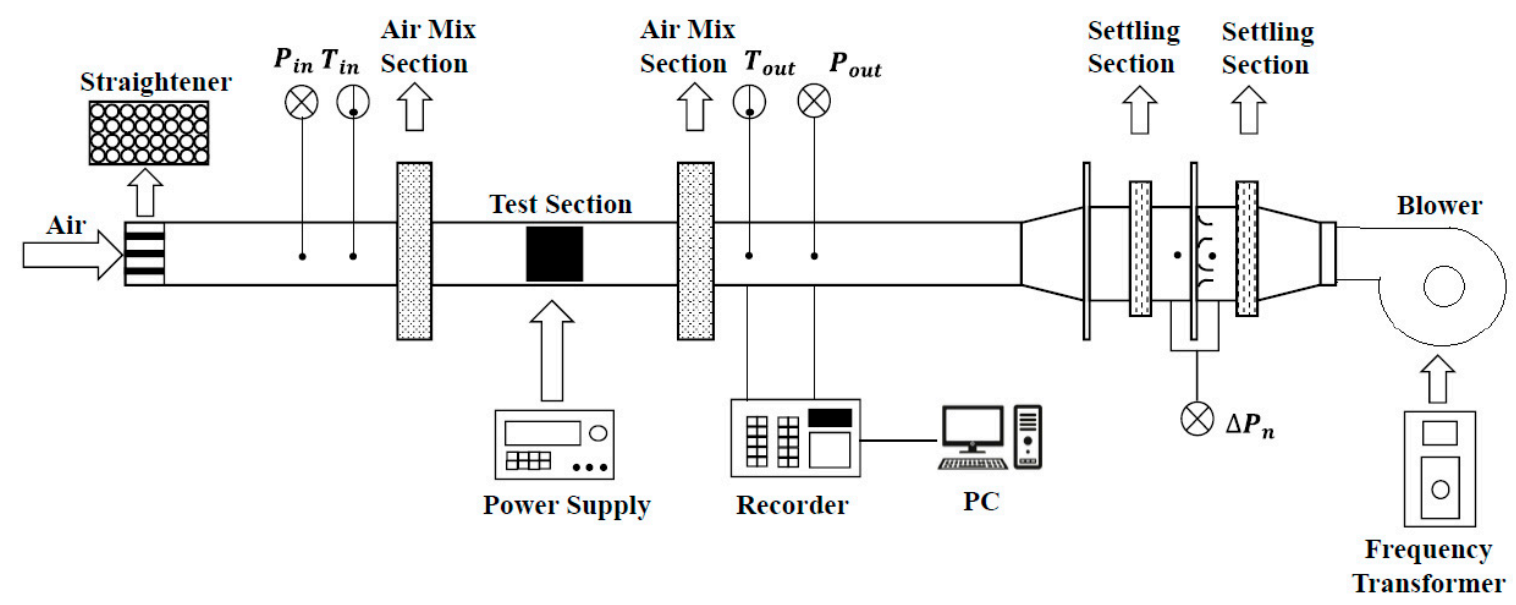

Figure 1. Schematic diagram of the wind tunnel in this study.

By applying both continuity equation and Bernoulli's equation across the nozzle with the fact that the cross-sectional area of the nozzle outlet $\left(7.13 \times 10^{-5} \mathrm{~m}^{2}\right)$ is much less than that of the wind tunnel $\left(0.042 \mathrm{~m}^{2}\right)$, the mass flow rate of the air, $\dot{m}$, through the wind tunnel can be estimated as:

$$
\dot{m}=\rho \cdot V_{n} \cdot A_{n}=\left(2 \rho \cdot \Delta P_{n}\right)^{1 / 2} A_{n}
$$

where $\rho, V_{n}, A_{n}$, and $\Delta P_{n}$ are the air density determined based on the film temperature, the air flow velocity through the nozzle, the cross-sectional area of the nozzle outlet, and the pressure drop across the nozzle, respectively. 
In addition, the following relation between the mass flow rate in the wind tunnel and the air frontal velocity through the plate-fin array, $V$, is also valid.

$$
\dot{m}=\rho \cdot V \cdot A_{c}=\rho \cdot V(n \cdot w \cdot H)
$$

where $A_{c}$ is the total cross-sectional area that allows the air to enter the plate-fin array without bypass that equals to the product of the number of the rectangular channel enclosed by two adjacent plates, $n$, and the fin pitch, $w$, as well as the fin height, $H$.

The geometries of the heat sink are shown in Figure 2a. Five heat sinks possessing either 16 plain plate-fins or 16 plate-fins having 4 rows of identical winglet VGs on each plate are shown in Figure $2 b$. The types of the winglet VGs fabricated on the plate-fins of the heat sinks in this study include rectangular winglet pair (RWP), delta winglet pair (DWP), swept delta winglet pair (SDWP), and swept trapezoid winglet pair (STWP), as shown in Figure 2c. The heat sinks are made of copper with thermal conductivity of $398 \mathrm{~W} / \mathrm{mK}$. The detailed dimensions of the heat sinks are tabulated in Table 1. The length and thickness of the square base plate of each heat sink are $45 \mathrm{~mm}$ and $2 \mathrm{~mm}$, respectively. The corresponding fin pitch and fin height of each heat sink are $2 \mathrm{~mm}$ and $10 \mathrm{~mm}$, respectively, with a constant fin thickness of $0.2 \mathrm{~mm}$. A copper block that was heated through the embedded heating cartridges powered by a power supply (GW Instek PSM-6003) was used as the heater by attaching to the heat sink base. A constant pressure of $10 \mathrm{kgf} / \mathrm{cm}^{2}$ was exerted on the heat sink for all tests to provide consistent thermal contact resistance between the heat sink and heater. In addition, the dimensions of the copper block were identical to those of the heat sink base. The copper block was placed in a sheath made of bakelite to minimizing the heat loss. During the tests, the power supply provided $20 \mathrm{~W}$ power input to the heater. A total of five thermocouples were used to measure the base temperature of heat sink. Detailed locations of the thermocouples' joints are indicated as red dots in Figure 3. The data were captured under steady state condition while the variation of the temperature on the heat sink base was less than $0.2^{\circ} \mathrm{C}$ within $30 \mathrm{~min}$.

Table 1. The detailed specification of the heat sink and the winglets.

\begin{tabular}{ccc}
\hline fin pitch, $w$ & $2 \mathrm{~mm}$ \\
\hline fin height, $H$ & $10 \mathrm{~mm}$ \\
\hline fin thickness, $t$ & $0.2 \mathrm{~mm}$ \\
\hline fin length, $L$ & $45 \mathrm{~mm}$ \\
\hline number of rectangular channel, $n$ & 16 \\
\hline winglet type & DWP & SDWP \\
\hline angle of attack, $\beta$ & $30^{\circ}$ \\
\hline winglet height, $h(\mathrm{~mm})$ & 1 \\
\hline vortex generator area, $A_{V G}\left(\mathrm{~mm}^{2}\right)$ & 4 \\
\hline $\begin{array}{c}\text { transverse distance between the } \\
\text { tip of the winglet pair, } s(\mathrm{~mm})\end{array}$ & 1 \\
\hline RWP: Rectangular Winglet Pair, DWP: Delta Winglet Pair, SDWP: Swept Delta Winglet Pair, \\
STWP: Swept Trapezoid Winglet Pair
\end{tabular}

The heat transfer rate from the tested heat sink to the airflow in the wind tunnel, $q$, was determined as follows:

$$
q=\dot{m} C_{p}\left(T_{\text {out }}-T_{\text {in }}\right)
$$


and the heat transfer coefficient, $h$, of the fin array was estimated as:

$$
h=\frac{q}{A_{t} \eta_{0}\left[T_{s}-\frac{\left(T_{\text {in }}-T_{\text {out }}\right)}{2}\right]}
$$

where $C_{p}, A_{t}, \eta_{0}, T_{s}, T_{\text {in }}$, and $T_{\text {out }}$ denote the specific heat of the air, the total surface area of the heat sink, the overall surface efficiency, the average temperature on the heat sink base, and the inlet and outlet air temperature of the test section, respectively. Since the fin efficiency is so high ( 0.95) because of the high thermal conductivity of the fin material, the overall surface efficiency, $\eta_{0}$, of the heat sink is assumed to be 1 in this study for simplicity.

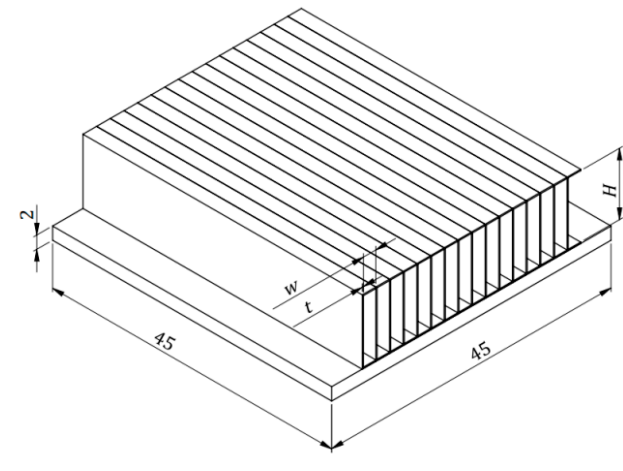

(a)

Fin types $\quad$ Air flow $\rightarrow$

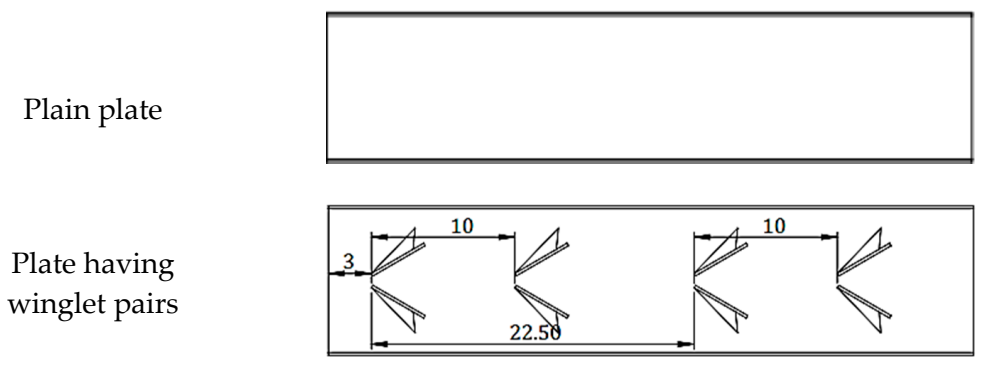

(b)

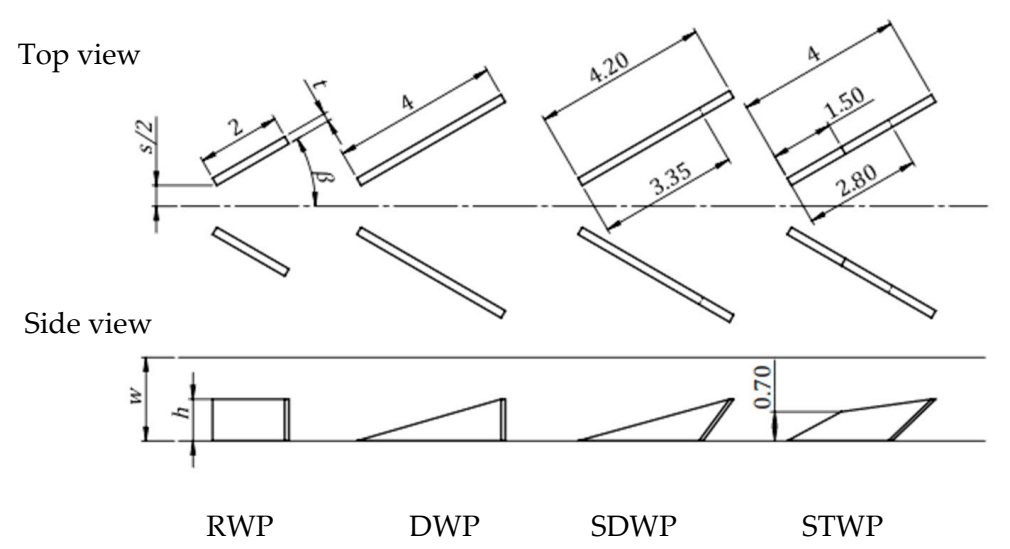

(c)

Figure 2. Tested heat sinks; (a) the exterior dimensions, (b) the arrangement of the four rows of winglet vortex generators (VGs), and (c) types of tested winglet VGs. 


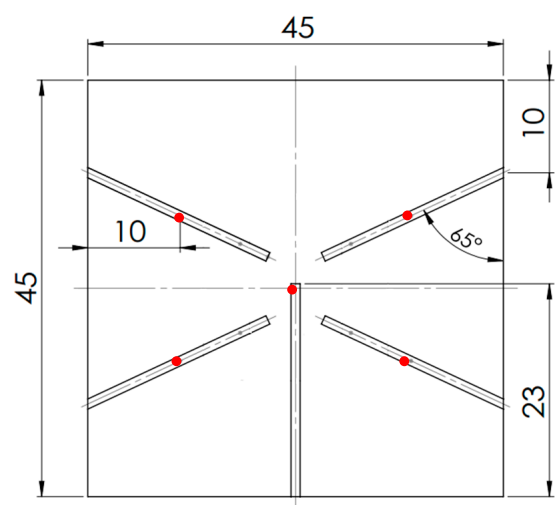

Figure 3. The location of the temperature measurement points on the heat sink base.

Once the pressure drop and the heat transfer coefficient of the heat sink are obtained, the dimensionless parameters including friction factor, $f$, and Nusselt number, $N u$, based on the hydraulic diameter, $D_{h}$, can thus be estimated by the following expressions,

$$
\begin{gathered}
f=\frac{\Delta P}{4\left(\frac{L}{D_{h}}\right) \cdot\left(\frac{\rho V^{2}}{2}\right)} \\
N u=\frac{h D_{h}}{k}
\end{gathered}
$$

where $\Delta P, L$, and $k$ denote the pressure drop across the heat sink, the fin length, and the thermal conductivity of air, respectively. The hydraulic diameter, $D_{h}$ is defined as:

$$
D_{h}=\frac{4 A_{c}}{P}=\frac{4(H \cdot w)}{2(H+w)}
$$

In addition, Prandtl number and Reynolds number listed below were also used to analyze the present measured data,

$$
\begin{gathered}
P r=\frac{v}{\alpha} \\
R e=\frac{V D_{h}}{v}
\end{gathered}
$$

where $v$ and $\alpha$ are kinematic viscosity and thermal diffusivity of air based on film temperature.

The uncertainty of the measured values estimated by a published method [26] is listed in Table 2.

Table 2. Uncertainty of the measured value in this study.

\begin{tabular}{ccc}
\hline \multirow{2}{*}{ Parameter } & \multicolumn{2}{c}{ Uncertainty } \\
\cline { 2 - 3 } & $\mathbf{1} \mathbf{~} / \mathbf{s}$ & $\mathbf{5} \mathbf{~} / \mathbf{s}$ \\
\hline$\Delta P$ & $0.23 \%$ & $0.36 \%$ \\
\hline$h$ & $0.15 \%$ & $0.27 \%$ \\
\hline$V$ & $1.09 \%$ & $1.09 \%$ \\
\hline$N u$ & $0.71 \%$ & $0.94 \%$ \\
\hline$f$ & $2.42 \%$ & $2.43 \%$ \\
\hline$R e$ & $1.50 \%$ & $1.49 \%$ \\
\hline$N u / N u_{0}$ & $1.00 \%$ & $1.32 \%$ \\
\hline$f / f_{0}$ & $3.43 \%$ & $3.44 \%$ \\
\hline$\left(N u / N u_{0}\right) /\left(f / f_{0}\right)^{1 / 3}$ & $1.15 \%$ & $1.15 \%$ \\
\hline
\end{tabular}




\section{Numerical Simulation}

Besides the experimental test on the heat sinks, 3-D numerical simulation using COMSOL Multiphysics ${ }^{\circledR} 5.2 \mathrm{a}$ was also performed to visualize the vortex structure generated by different types of winglet pairs and to obtain the air temperature distribution close to the plate-fin surface. Because the geometry, heat, and fluid flow condition for each rectangular channel bound by two adjacent plates is similar, only two of the adjacent rectangular channels incorporating two copper plate-fins with a 2-mm-thick base were designated as the computational domain shown in Figure 4a. The holes on the plate-fin because of the punching process to achieve the winglets are present only on the central plate-fin.

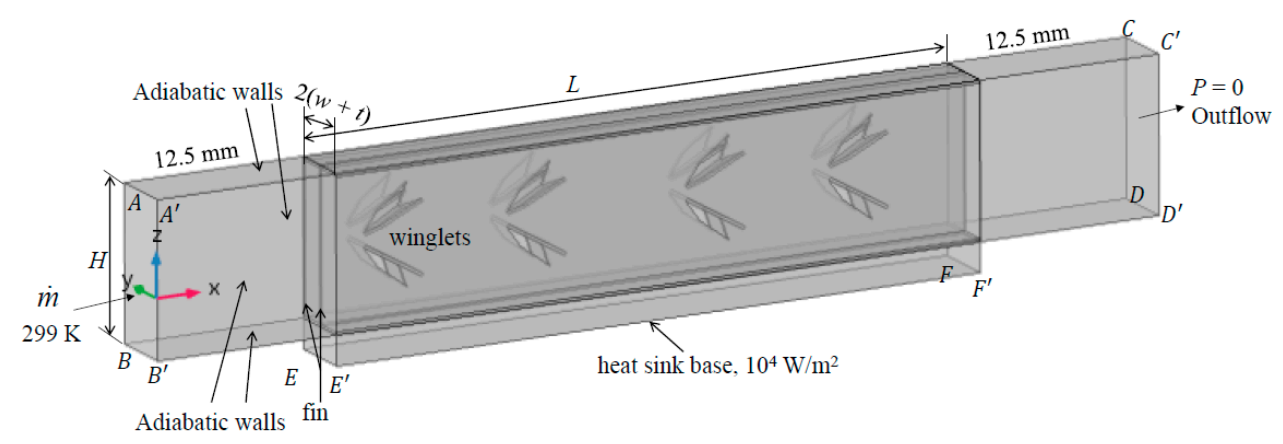

(a)

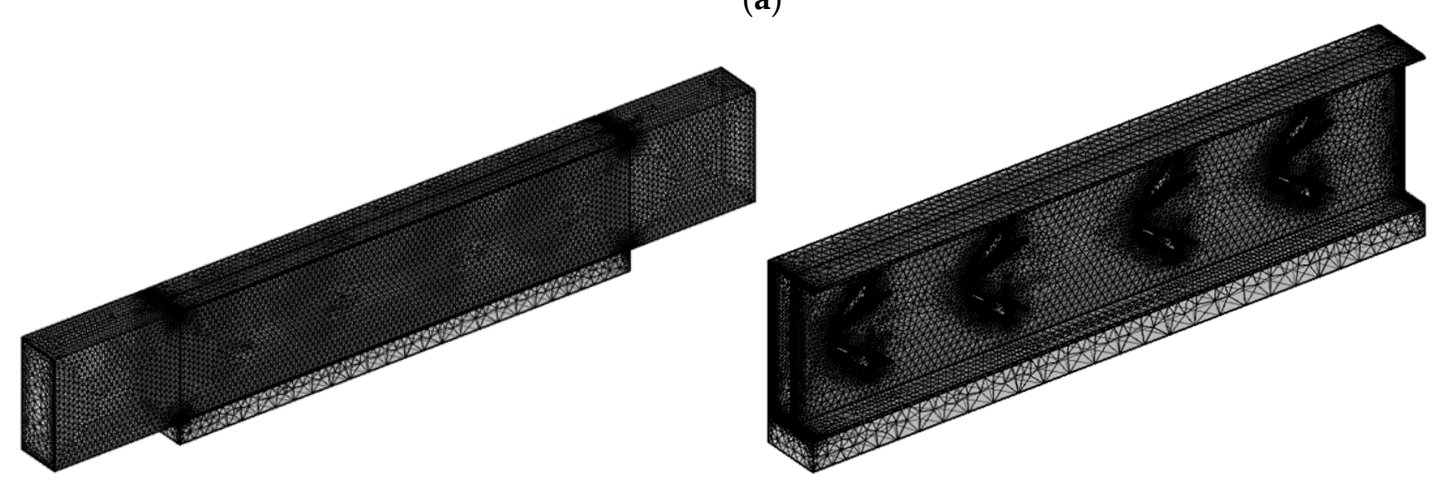

(b)

Figure 4. (a) The computational domain, and (b) the mesh for the plate-fin heat sink having 4 rows of winglet VGs.

Radiation heat transfer and body force are neglected in the physical model. Airflow is considered as incompressible, laminar flow as the corresponding Mach number and Reynolds number are always less than 0.015 and 2300, respectively. The velocity and temperature were uniform at the inlet. The compact forms of governing equations under steady state are listed below.

$$
\begin{gathered}
\frac{\partial\left(\rho_{f} u_{i}\right)}{\partial x_{i}}=0 \\
\frac{\partial}{\partial x_{i}}\left(\rho_{f} u_{i} u_{j}\right)=-\frac{\partial p}{\partial x_{j}}+\frac{\partial}{\partial x_{i}}\left(\mu \frac{\partial u_{j}}{\partial x_{i}}\right) \\
\frac{\partial}{\partial x_{i}}\left(\rho_{f} C_{p, f} u_{i} T\right)=\frac{\partial}{\partial x_{i}}\left(k_{f} \frac{\partial T_{f}}{\partial x_{i}}\right) \\
\frac{\partial}{\partial x_{i}}\left(k_{s} \frac{\partial T_{s}}{\partial x_{i}}\right)=0
\end{gathered}
$$


where the subscripts $f$ and s denote fluid and solid, respectively. The boundary conditions provided in this study are as follows. The given mass flow rates are specified at the inlet (face $A A^{\prime} B^{\prime} B$ ), where the flow velocity is uniform over the cross-section, to reflect the various frontal air velocities. The inlet temperature is $299 \mathrm{~K}$, while both the adiabatic and no-slip, as well as impermeable boundary conditions were imposed respectively on the left (face $A B D C$ ), right (face $A^{\prime} B^{\prime} D^{\prime} C^{\prime}$ ), and top and bottom surfaces of the computational domain, except the heat sink base. The outlet (face $C C^{\prime} \mathrm{D}^{\prime} \mathrm{D}$ ) was specified as both zero gage pressure and zero temperature gradient along the flow direction. A constant heat flux, $10^{4} \mathrm{~W} / \mathrm{m}^{2}$ was specified on the bottom surface of the heat sink base (face $E^{\prime} \mathrm{F}^{\prime} \mathrm{F}$ ). The present computational domain was discretized with a tetrahedral mesh and the mesh was refined near the VGs and solid surface, as shown in Figure $4 \mathrm{~b}$. The finite element method was employed to investigate the fluid flow and heat transfer characteristics. Taking the memory requirements of the computation into account, the segregated solutions were used to combine with three separate steps. The solutions of variables were calculated by the linear iterative solver GMRES, and the convergence criteria for the residual was set as $10^{-2}$.

Grid independence was ensured by testing numerous sets of meshes for the computational domain. Once the differences in the Colburn $j$ factor, which is defined as $j=\frac{N u}{\operatorname{Re} P r^{1 / 3}}$, between two successive sets of meshes was less than $5 \%$, the grid independence was considered to be achieved. The final solutions were obtained with mesh elements of about 320,000 and 1,500,000 for plate-fin heat sink and plate-fin heat sink having 4 rows of winglet VGs, respectively.

\section{Result and Discussion}

\subsection{Validation of Experimental Results}

In order to validate the present measured results, the measured pressure drop and heat transfer coefficient of the plain plate-fin heat sink were compared with the predicted values estimated by the published correlations [27] under similar conditions. Figure 5 shows the comparison of the Nusselt number between the predicted value and the measured data at various Reynolds numbers using fin pitch as the characteristic lengths, $N u_{w}$ and $R e_{w}$. In addition, the simulation result is also plotted in Figure 5. It shows that the Nusselt numbers obtained from the experiment and the numerical simulation are in a good agreement with the predicted Nusselt number presented as the curve without symbol in Figure 5. The deviation between the measured Nusselt number and the predicted value is gradually reduced from $30 \%$ to $5 \%$ with the increase of Reynolds number.

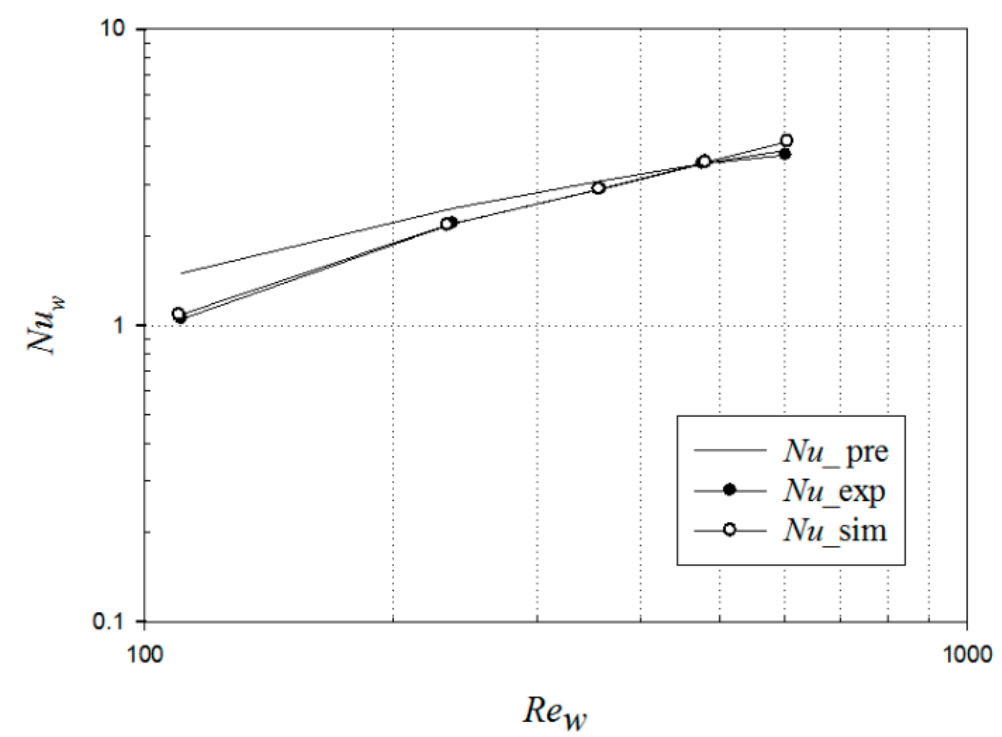

Figure 5. Nusselt number vs. Reynolds number of the plain plate-fin heat sink obtained by prediction, experimental measurement, and numerical simulation. 
The comparison of the friction factor of the plain plate-fin heat sink between the measured values and the values predicted by the correlation [28], which employs the square root of the cross-sectional area as characteristic length and includes the aspect ratio of the channel to minimize the effect of channel shape on the friction factor prediction, is also made in Figure 6. Figure 6 shows that the deviation between both curves lies between $6 \%$ and $11 \%$, which is approximately the same as the accuracy of the correlation. Based on the results revealed in both Figures 5 and 6, the measured data in this study should be reliable.

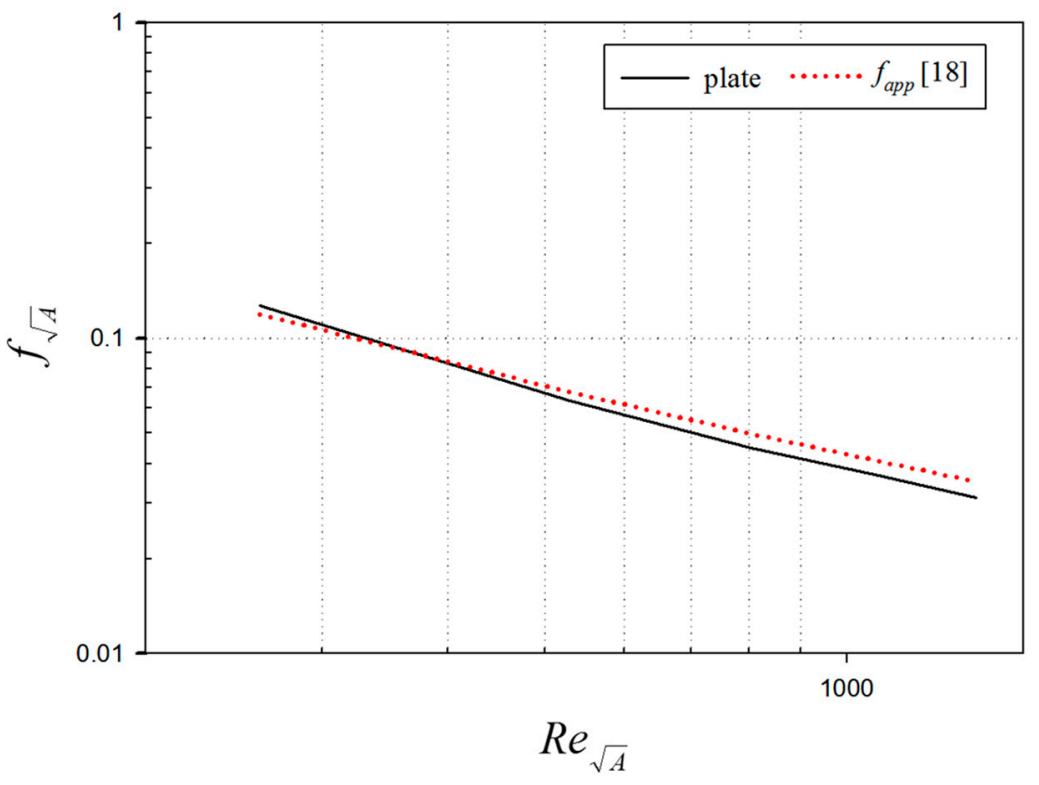

Figure 6. Friction factor vs. Reynolds number of the plain plate-fin heat sink obtained by prediction (red dashed curve) and the experiment (solid curve).

\subsection{Measured Results of the Heat Sinks}

The pressure drop of the heat sinks in this study at airflow velocity in a range of $1 \mathrm{~m} / \mathrm{s} \leq \mathrm{V} \leq 5 \mathrm{~m} / \mathrm{s}$ is plotted in Figure 7a. It can be seen in Figure 7 that the air pressure drop across the heat sink increased as the airflow velocity was increased. Besides that, the pressure drop of the heat sink having DWP or SDWP was higher than that of the heat sinks having RWP or STWP. Since the airflow passing the heat sink was affected by the existing VGs, the resulting heat transfer coefficient of all heat sinks having VGs was significantly enhanced, as shown in Figure $7 \mathrm{~b}$. At air velocity of $5 \mathrm{~m} / \mathrm{s}$, the heat transfer coefficient of the plain plate-fin heat sink was about $50 \mathrm{~W} / \mathrm{m}^{2} \mathrm{~K}$, while that of the heat sinks having VGs was between $67 \mathrm{~W} / \mathrm{m}^{2} \mathrm{~K}$ and $70 \mathrm{~W} / \mathrm{m}^{2} \mathrm{~K}$. 


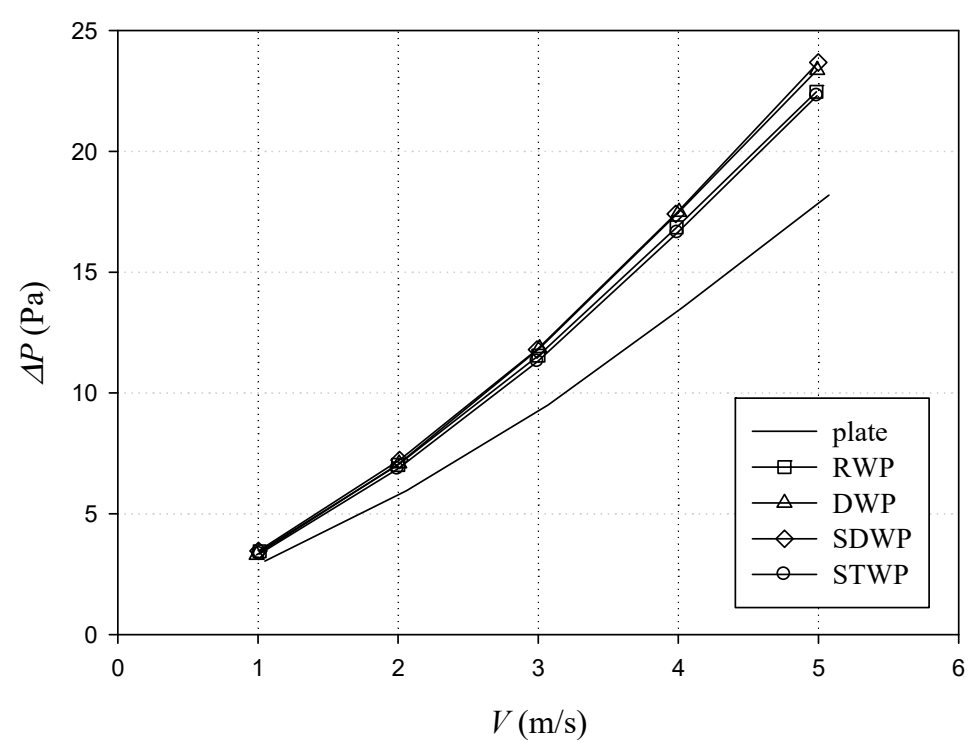

(a)

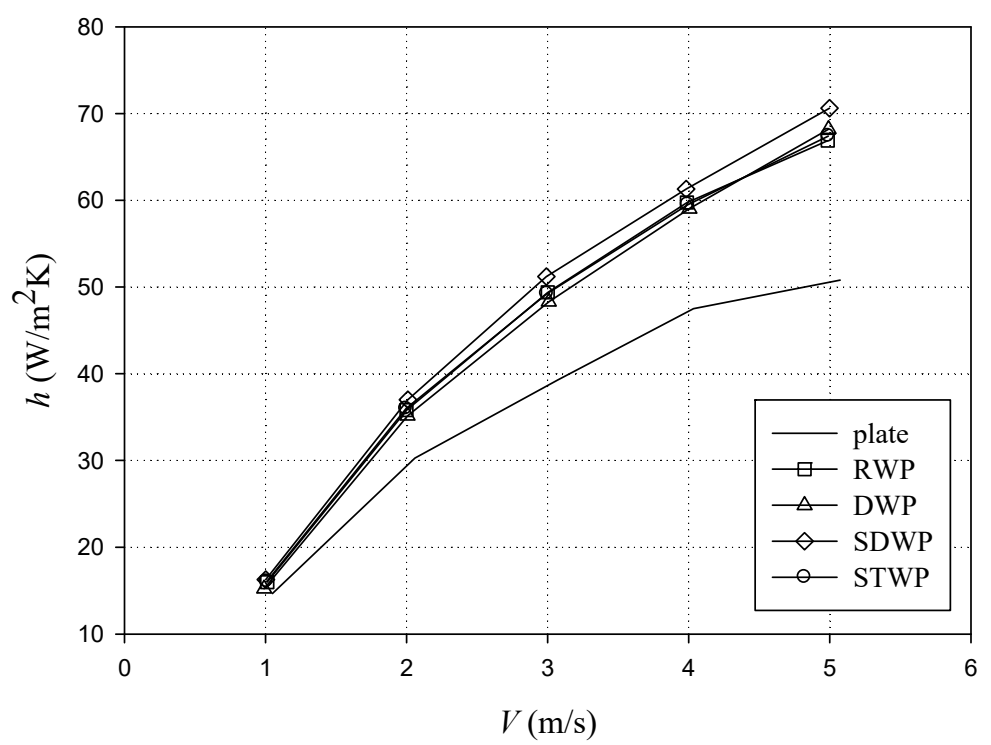

(b)

Figure 7. The measured (a) pressure drop and (b) heat transfer coefficient of the tested heat sinks at a frontal air velocity ranging from $1 \mathrm{~m} / \mathrm{s}$ to $5 \mathrm{~m} / \mathrm{s}$.

\subsection{Simulation Results}

The simulation results to show both the vortices velocity on several $y z$ planes between the first two rows of the winglet pairs and the air temperature distribution on a $x z$ plane that is $1 \mathrm{~mm}$ above the plate-fin surface are presented in Figure 8. Note that the first $y z$ plane lies in the trailing edge of the first row of winglet and the distance between two adjacent $y z$ planes is always $2 \mathrm{~mm}$. A pair of longitudnal vortex in common-flow-down configuration can be clearly seen behind each type of winglet pair, causing higher pressure drop and heat transfer coefficient than those of the plain plate-fin heat sink in Figure 7. In addition, the temperature distribution on the $x z$ plane in Figure 8 shows that the region behind each winglet where the downwash of the vortex impinges on and sweeps over results in noticeably low air temperature. A thinner thermal boundary layer over the region is responsible for the low air temperature that will be shown in Figure 9. 
However, a slight differnce in the location of the low temperature region relative to the winglet pair can be observed between the RWP in Figure 8a and the others in Figure 8b-d. The cool air caused by the longitudinal vortices behind RWP mainly distributes along the centerline between each pair of the winglets, while that caused by the vortices behind the other types of winglets always lies in both sides with respect to the centerline. In order to keep identical area and angle of attack of each type of winglets as listed in Table 1, the chord of the RWP is shorter and the space between the trailing edges of the winglet pair is narrower than the other types of winglets, as shown in Figure 2c, leading to a restricted vortex development. The temperature distribution on the $x z$ plane displayed in Figure 8a-d at airflow velocity of $5 \mathrm{~m} / \mathrm{s}$ indicates the air temperature profile caused by RWP on the bottom surface ( $x z$ plane) would be different from that caused by other types of winglets. It is confirmed by the temperature distribution on several yz planes exhibited in Figure 9. As mentioned above, the thinnest warm air layer occurs in the centerline between the RWP, while that occurs near the trailing edge of the other types of winglets.

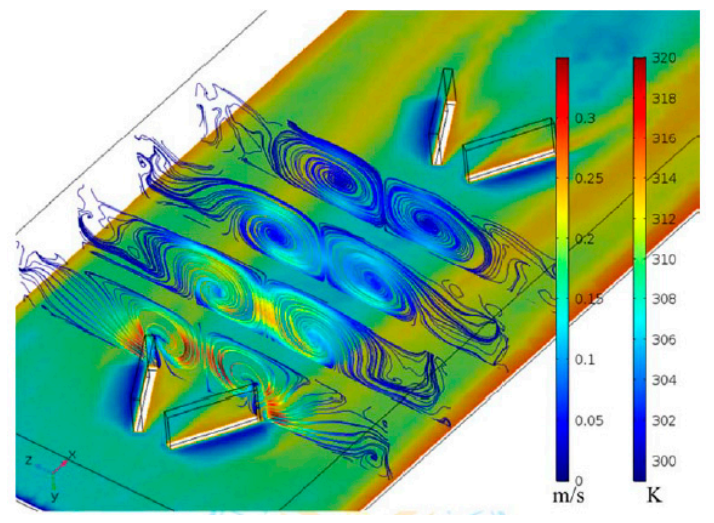

(a)

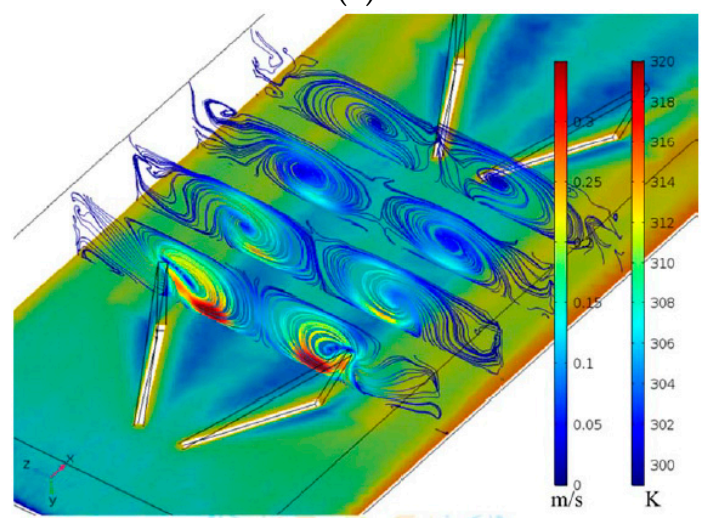

(c)

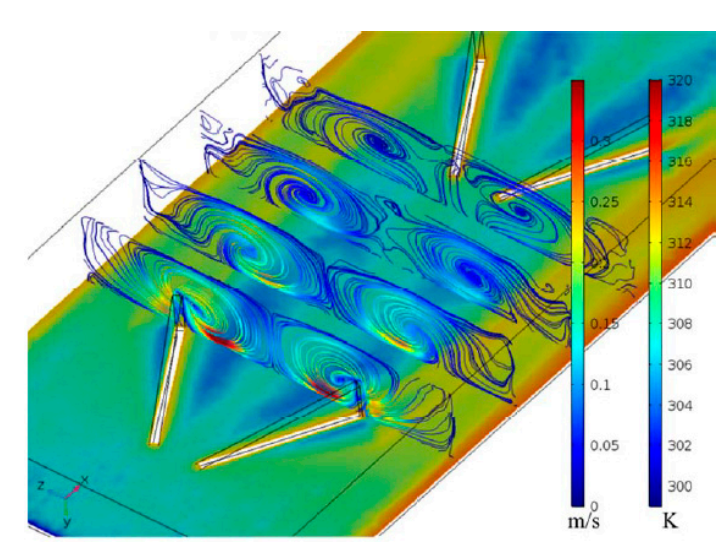

(b)

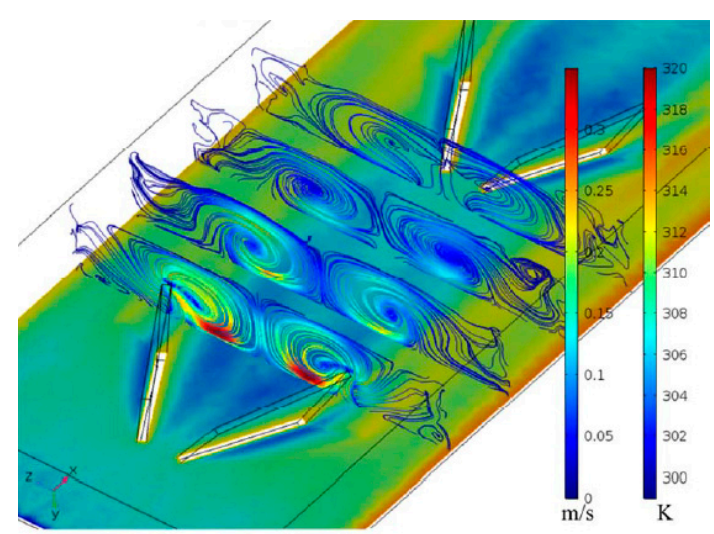

(d)

Figure 8. Vortex velocity on several yz planes between the first two rows of VGs and the resulting air temperature distribution on a $x z$ plane that is $0.1 \mathrm{~mm}$ above the solid fin surface for the plate-fin with (a) rectangular winglet pair (RWP), (b) delta winglet pair (DWP), (c) swept delta winglet pair (SDWP), and (d) swept trapezoid winglet pair (STWP) at airflow velocity of $5 \mathrm{~m} / \mathrm{s}$. 


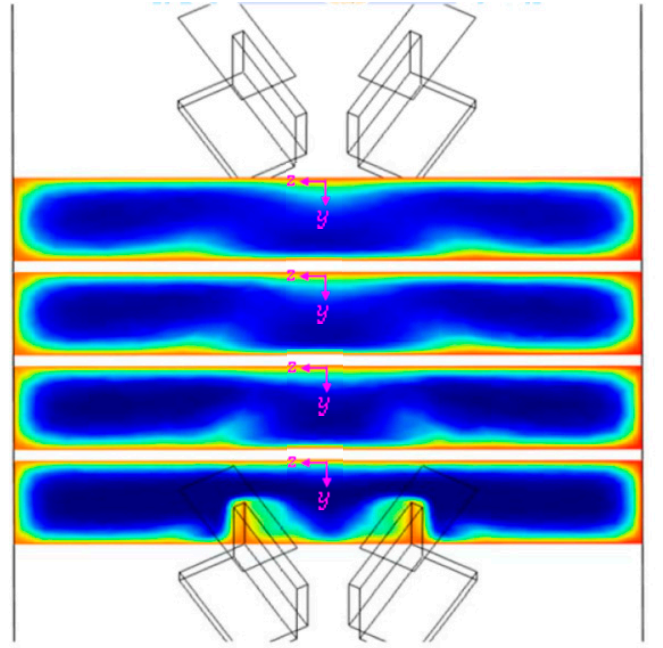

(a)

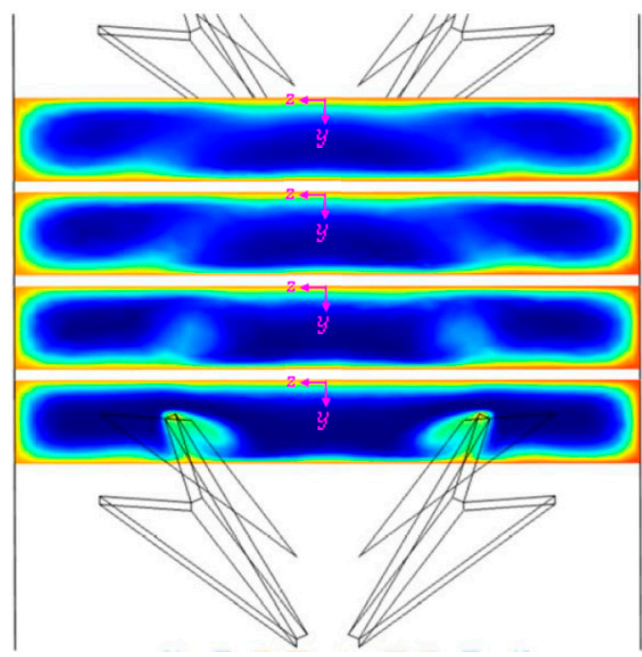

(c)

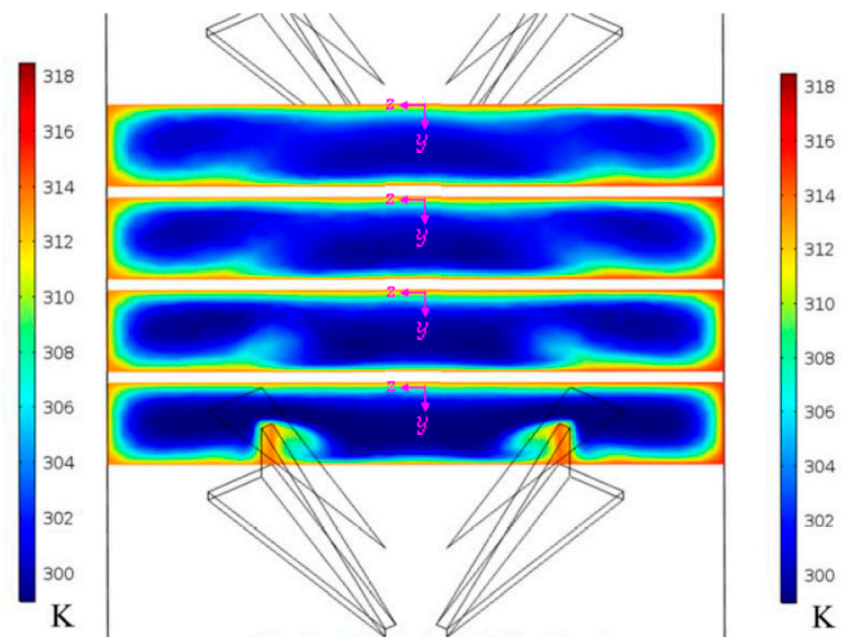

(b)

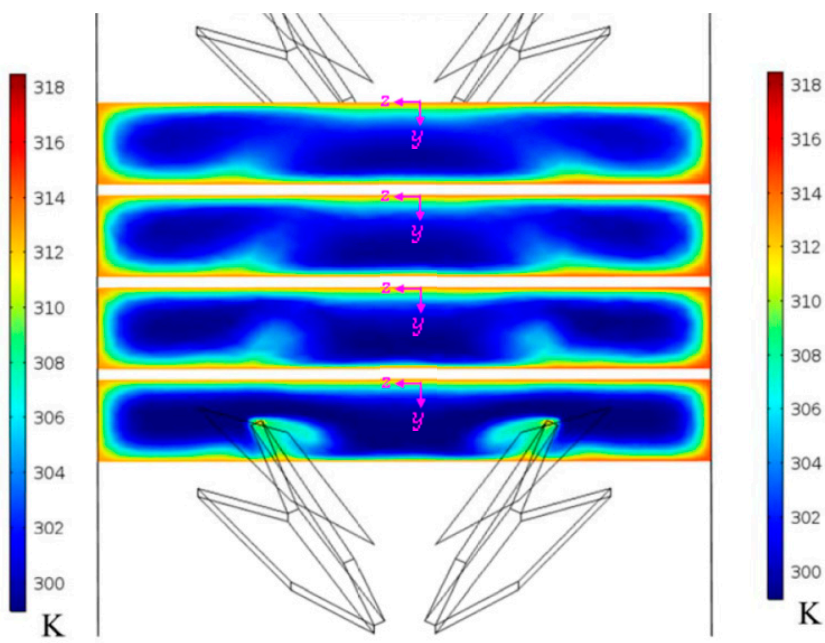

(d)

Figure 9. The air temperature distribution in several yz planes of the plate-fin heat sinks having (a) RWP,

(b) DWP, (c) SDWP, and (d) STWP VGs at airflow velocity of $5 \mathrm{~m} / \mathrm{s}$.

The air temperature distribution at airflow velocity of $5 \mathrm{~m} / \mathrm{s}$ above a complete plate in Figure 10 shows that the upstream winglet pair causes stronger heat transfer enhancement than the downstream winglet pair do, according to the inspection of both the air temperature profile behind each row of the winglet pair and the area of the low air temperature region. Since the vortex is able to last far downstream once the vortex is generated as revealed in Figure 8, a dense arrangement of vortex generators may not be necessary and the decrease in the number of winglet pairs is likely to yield similar average heat transfer coefficient with less pressure drop. In addition, the in-line arrangement of the winglets causes the air temperature on the region between the trailing edge of those winglets and the channel boundary to rise as shown in Figure 10, as the air flows downstream. 


\begin{tabular}{|c|}
\hline RWP \\
\hline DWP \\
\hline SDW \\
\hline $\mathrm{P}$ \\
\hline STW \\
\hline \\
\hline
\end{tabular}

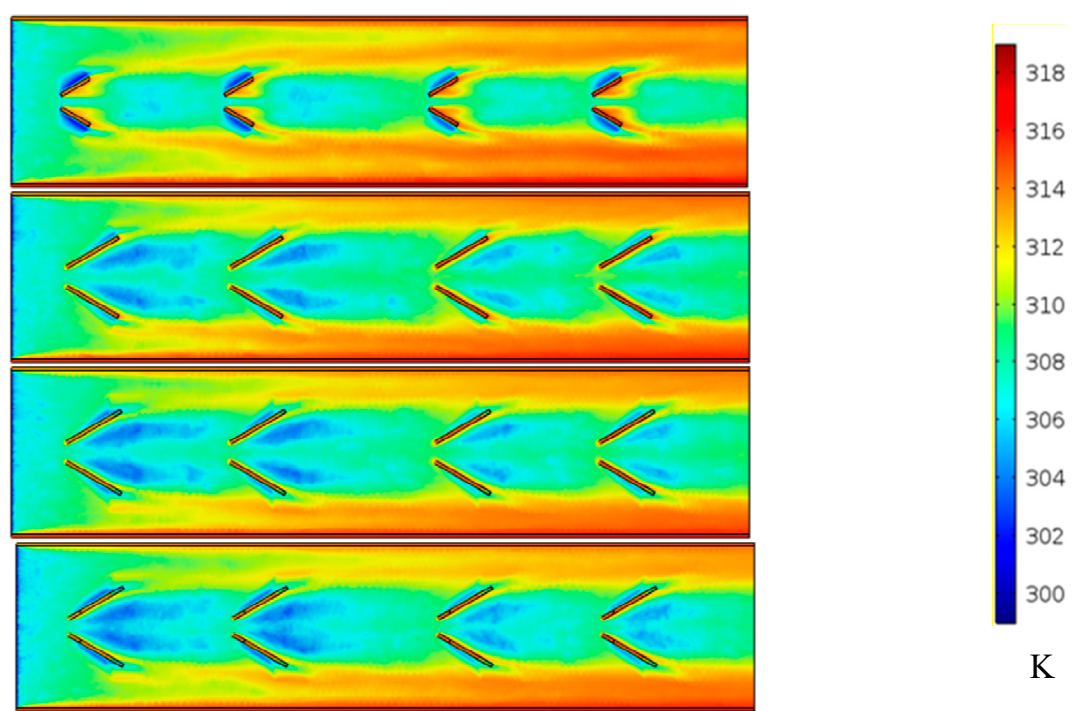

Figure 10. Air temperature distribution on an entire $x z$ plane that is $0.1 \mathrm{~mm}$ above the solid fin surface for the plate-fin with (a) RWP, (b) DWP, (c) SDWP, and (d) STWP VGs at an airflow velocity of 5 m/s.

\subsection{Performance Evaluation of the Heat Sinks}

In order to evaulate the heat transfer enhancement of the heat sinks in this study, the ratio of the Nusselt number of those heat sinks having VGs to that of the heat sink without VGs, $N u_{0}$, is plotted in Figure 11 with respect to Reynolds number. It shows that the normalized Nusselt number of the heat sink having SDWP is the highest, while that of the heat sink having DWP is the lowest until the Reynolds number exceeds 800. Besides that, the normalized Nusselt number in Figure 11 is similar between RWP and STWP at all Reynolds numbers. By examining the simulation results, it can be observed that the sweptback design of the SDWP and STWP seems to induce additional vortices in the right and left corners of the channel, starting from the location where the rear edge of the winglet begins to extend backward. The second pair of vortices can also be found in RWP because the short chord enables the space between trailing edge of the VGs and the channel edge to generate the second pair of votrices in the left and right corners of the channel. As for DWP, the second pair of vortices would be diffcult to be generated until Reynolds number of the airflow is high enough, say 800. In general, the normalized Nusselt number is increased with the increase of Reynolds number, except the local minimum at Reynolds number around 800 in Figure 9. In fact, as Reynolds number reached approximately 800, the reciprocal of Graetz number defined as $\frac{1}{G z}=\frac{L / D_{h}}{\operatorname{Re} P r}$ would be less than 0.05 , indicating the fact that the thermal entry length of the airflow would be longer than the fin length as Reynolds number exceeds 800 . Since the vortices generated behind the winglets are able to affect the development of the thermal boundary layer over the plate as exhibited on the bottom surface in Figure 9, the concept of the thermal fully developed flow would not be applicable to the heat sink having VGs, causing the monotonously increasing curves in Figure $7 \mathrm{~b}$ without an apparent transition at airflow velocity of $4 \mathrm{~m} / \mathrm{s}$. Figure 11 shows that the normalized Nusselt numbers are approximately 1.1 and 1.4 when testing the heat sink with SDWP at Reynolds numbers of 200 and 1000, respectively.

It has been confirmed in Figure 7 that both the pressure drop across the heat sink and the heat transfer coefficient of the heat sink could be increased simultaneously as the plate-fin is fabricated with winglets. Therefore, the thermal enhancement factor, TEF, of the present heat sinks based on identical pumping power [18] was estimated using Equation (14) to evaluate the heat transfer performance of the present heat sinks at different Reynolds number.

$$
T E F=\frac{\left(N u / N u_{0}\right)}{\left(f / f_{0}\right)^{1 / 3}}
$$


Note that the subscript 0 denotes the value for plain plate-fin heat sink, and $N u$ and $f$ represent the Nusselt number and friction factor of the heat sinks. The TEF plotted in Figure 12 shows that the heat sink having SDWP would be the best one among all, yielding TEF values of about 1.03 and 1.28 at Reynolds numbers of about 200 and 1000, respectively. Note that the TEF of the IPWP design in the simulation results [18] was 1.0 and 1.2 at Reynolds number of about 300 and 1000, respectively.

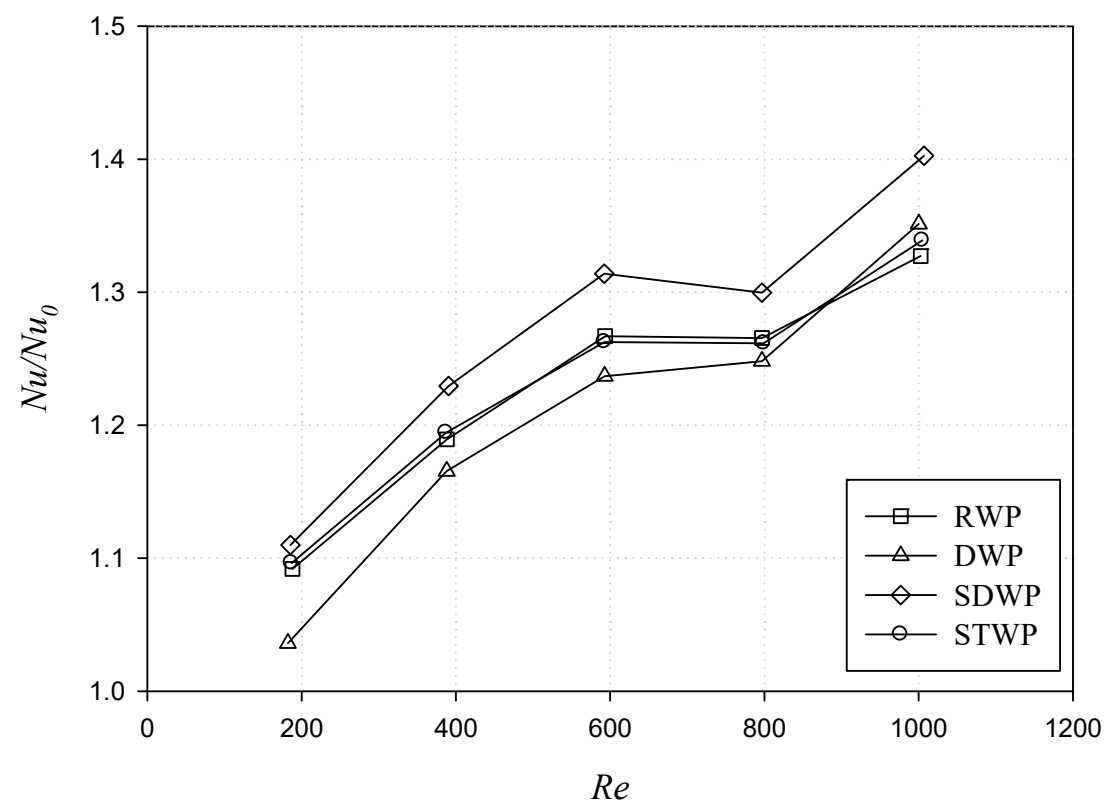

Figure 11. Variation of $N u / N u_{0}$ vs. Re of all heat sinks having VGs in this study.

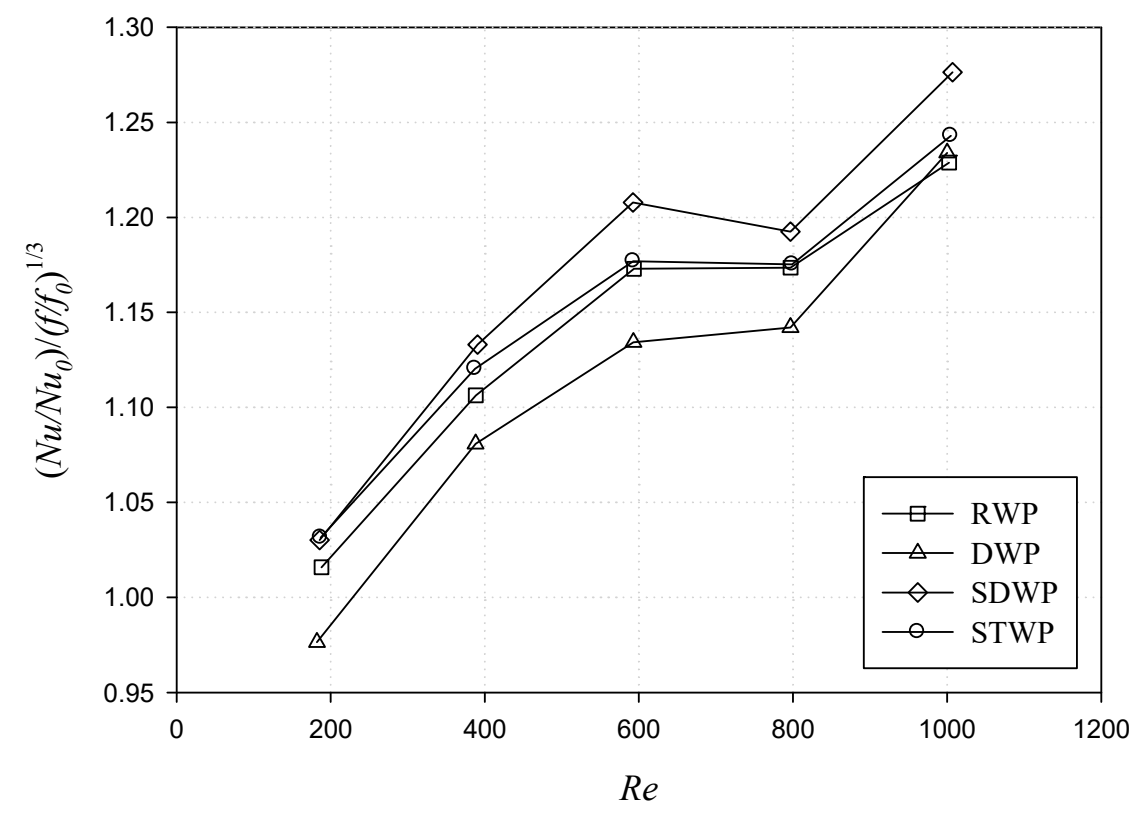

Figure 12. Thermal enhancement factor vs. Re for the heat sinks having different types of VGs.

\section{Conclusions}

In this study, both Nusselt number and friction factor, as well as the thermal enhancement factor of the plate-fin heat sinks with different types of winglet pairs as vortex generators were tested. The projected area, angle of attack and the height of the winglets, and the arrangement of the 4 rows of winglet pairs on each plate-fin were identical for all heat sinks. The air was forced across the test heat sink with the bottom being uniformly heated at a fixed heating power in a parallel way at airflow 
velocity ranging from $1 \mathrm{~m} / \mathrm{s}$ to $5 \mathrm{~m} / \mathrm{s}$ without bypass. Besides this experiment, three-dimensional numerical simulation was also performed in order to discuss the vortices effect on the thermal and hydraulic performance of the heat sinks. The results are summarized as follows.

1. Both the pressure drop and heat transfer coefficient of those heat sinks having winglet VGs were augmented, compared to those of the plain plate-fin heat sink. At air velocity of $5 \mathrm{~m} / \mathrm{s}$, the heat transfer coefficient of the plain plate-fin heat sink was about $50 \mathrm{~W} / \mathrm{m}^{2} \mathrm{~K}$, while that of the heat sinks having winglet VGs was between $67 \mathrm{~W} / \mathrm{m}^{2} \mathrm{~K}$ and $70 \mathrm{~W} / \mathrm{m}^{2} \mathrm{~K}$.

2. Whatever the type of winglets tested, the simulation result showed that the heat transfer enhancement attributed to the VGs was gradually weakened as the air flowed downstream. It suggests that optimizing the number and arrangement of the winglets might result in similar or higher heat transfer coefficient with lower pressure drop.

3. The heat sink having SDWP yielded the best heat transfer performance among other types of VGs in this study. Its Nusselt number was increased by a factor of $40 \%$ compared to that of the heat sink without VGs. The normalized Nusselt number versus Reynolds number showed a local minimum at $R e=800$ for all types of heat sinks, indicating a transition between thermally fully developed flow and developing flow.

4. The thermal enhancement factor which considers Nusselt number together with friction factor of the tested heat sinks indicated that the best VGs were SDWP with TEF of 1.28 at Reynolds number of 1000, followed by RWP and STWP, and DWP was the worst in this study, in the range $200 \leq \operatorname{Re} \leq 1000$.

Since the heat flux generated by IGBT used in current HEVs have been addressed using advanced liquid cooling devices in single-phase or two-phase flow. The current study examining the heat transfer of heat sinks possessing VGs in forced air cooling forms a foundation of the future work regarding liquid cooling with VGs in an optimal arrangement in single-phase or two-phase flow.

Author Contributions: Investigation, J.-C.S. and J.-S.J.; Writing-original draft, J.-C.S.; Writing-review \& editing, J.-C.S. All authors have read and agreed to the published version of the manuscript.

Funding: This research was funded by the Ministry of Science and Technology of Taiwan, grant number MOST 107-2221-E-992-077-MY2 and MOST 108-2628-E-992-001-MY3.

Acknowledgments: The authors are indebted to the Ministry of Science and Technology of Taiwan for the funding under the contracts of MOST 107-2221-E-992-077-MY2 and MOST 108-2628-E-992-001-MY3.

Conflicts of Interest: The authors declare no conflict of interest.

\section{References}

1. Remsburg, R.; Hager, J. Direct Integration of IGBT Power Modules to Liquid Cooling Arrays; Electric Vehicle Symposium: Los Angeles, CA, USA, 2007.

2. Rajashekara, K. Present status and future trends in electric vehicle propulsion technologies. IEEE Trans. Emerg. Sel. Top. Power Electron. 2013, 1, 3-10. [CrossRef]

3. Morozumi, A.; Gohara, H.; Momose, F.; Saito, T.; Nishimura, Y.; Mochizuki, E.; Takahashi, Y. Next-generation IGBT module structure for hybrid vehicle with high cooling performance and high temperature operation. In Proceedings of the 2014 International Power Electronics Conference, Hiroshima, Japan, 18-21 May 2014.

4. Hussein, K.; Ishihara, M.; Miyamoto, N.; Nakata, Y.; Nakano, T. New compact, high performance 7th Generation IGBT module with direct liquid cooling for EV/HEV inverters. In Proceedings of the 2015 IEEE Applied Power Electronics Conference and Exposition (APEC), Charlotte, NC, USA, 15-19 March 2015; IEEE: Piscataway, NJ, USA, 2015.

5. Qian, C.; Gheitaghy, A.M.; Fan, J.J.; Tang, H.Y.; Sun, B.; Ye, H.Y.; Zhang, G.Q. Thermal Management on IGBT Power Electronic Devices and Modules. IEEE Access 2018, 6, 12868-12884. [CrossRef] 
6. Nonneman, J.; T’Jollyn, I.; Clarie, N.; Weckx, S.; Sergeant, P.; De Paepe, M. Model-Based Comparison of Thermo-Hydraulic Performance of Various Cooling Methods for Power Electronics of Electric Vehicles. In Proceedings of the 17th IEEE Intersociety Conference on Thermal and Thermomechanical Phenomena in Electronic Systems (ITherm), San Diego, CA, USA, 29 May-1 June 2018.

7. Wang, C.C. A quick overview of compact air-cooled heat sinks applicable for electronic cooling-Recent progress. Inventions 2017, 2, 5. [CrossRef]

8. Johnson, T.; Joubert, P. The influence of vortex generators on the drag and heat transfer from a circular cylinder normal to an airstream. J. Heat Transf. 1969, 91, 91-99. [CrossRef]

9. Patankar, S.V.; Prakash, C. An analysis of the effect of plate thickness on laminar flow and heat transfer in interrupted-plate passages. Int. J. Heat Mass Transf. 1981, 24, 1801-1810. [CrossRef]

10. Biswas, G.; Chattopadhyay, H. Heat transfer in a channel with built in wing type of vortex generators. Int. J. Heat Mass Transf. 1992, 35, 803-814. [CrossRef]

11. Tiggelbeck, S.; Mitra, N.K.; Fiebig, M. Experimental investigation of heat transfer enhancement and flow losses in a channel with double rows of longitudinal vortex generators. Int. J. Heat Mass Transf. 1993, 36, 2327-2337. [CrossRef]

12. Tiggelbeck, S.; Mitra, N.; Fiebig, M. Comparison of wing-type vortex generators for heat transfer enhancement in channel flows. J. Heat Transf. 1994, 116, 880-885. [CrossRef]

13. Biswas, G.; Torri, K.; Fujji, D.; Nishino, K. Numerical and Experimental determination of flow structure and heat transfer effects of longitudinal vortices in a channel flow. Int. J. Heat Mass Transf. 1996, 39, 3441-3451. [CrossRef]

14. Wu, J.M.; Tao, W.Q. Numerical study on laminar convection heat transfer in a channel with longitudinal vortex generator. Part B: Parametric study of major influence factors. Int. J. Heat Mass Transf. 2008, 51, 3683-3692. [CrossRef]

15. Tian, L.; He, Y.; Lei, Y. Numerical study of fluid flow and heat transfer in a flat plate channel with longitudinal vortex generators by applying field synergy principle analysis. Int. Commun. Heat Mass Transf. 2009, 36, 111-120. [CrossRef]

16. Violato, D.; Ianiro, A.; Cardone, G.; Scarano, F. Three-dimensional vortex dynamics and convective heat transfer in circular and chevron impinging jets. Int. J. Heat Fluid Flow 2012, 37, 22-36. [CrossRef]

17. Li, L.; Du, X.; Zhang, Y.; Yang, L.; Yang, Y. Numerical simulation on flow and heat transfer of fin-and-tube heat exchanger with longitudinal vortex generators. Int. J. Therm. Sci. 2015, 92, 85-96. [CrossRef]

18. Oneissi, M.; Habchi, C.; Russeil, S.; Bougeard, D.; Lemenand, T. Novel design of delta winglet pair vortex generator for heat transfer enhancement. Int. J. Therm. Sci. 2016, 109, 1-9. [CrossRef]

19. Zhou, G.; Feng, Z. Experimental investigations of heat transfer enhancement by plane and curved winglet type vortex generators with punched holes. Int. J. Therm. Sci. 2014, 78, 26-35. [CrossRef]

20. Esmaeilzadeh, A.; Amanifard, N.; Deylami, H. Comparison of simple and curved trapezoidal longitudinal vortex generators for optimum flow characteristics and heat transfer augmentation in a heat exchanger. Appl. Therm. Eng. 2017, 125, 1414-1425. [CrossRef]

21. Kashyap, U.; Das, K.; Debnath, B.K. Effect of surface modification of a rectangular vortex generator on heat transfer rate from a surface to fluid: An extended study. Int. J. Therm. Sci. 2018, 134, 269-281. [CrossRef]

22. Lu, G.; Zhai, X. Effects of curved vortex generators on the air-side performance of fin-and-tube heat exchangers. Int. J. Therm. Sci. 2019, 136, 509-518. [CrossRef]

23. Han, H.; Wang, S.; Sun, L.; Li, Y.; Wang, S. Numerical study of thermal and flow characteristics for a fin-and-tube heat exchanger with arc winglet type vortex generators. Int. J. Refrig. 2019, 98, 61-69. [CrossRef]

24. ASHRAE Handbook Fundamental; American Society of Heating, Refrigerating and Air-Conditioning Engineers: Atlanta, GA, USA, 1993; pp. 13.14-13.15.

25. ASHRAE Standard 41.2-1987, Standard Methods for Laboratory Air-Flow Measurement; American Society of Heating, Refrigerating and Air-Conditioning Engineers: Atlanta, GA, USA, 1987.

26. Moffat, R.J. Describing the uncertainties in experimental results. Exp. Therm. Fluid Sci. 1988, 1, 3-17. [CrossRef] 
27. Teertstra, P.; Yovanovich, M.M.; Culham, J.R. Analytical forced convection modeling of plate-fin heat sinks. J. Electron. Manuf. 2000, 10, 253-261. [CrossRef]

28. Muzychka, Y.S.; Yovanovich, M.M. Laminar forced convection heat transfer in the combined entry region of non-circular ducts. J. Heat Transf. 2004, 126, 54-61. [CrossRef]

(C) 2020 by the authors. Licensee MDPI, Basel, Switzerland. This article is an open access article distributed under the terms and conditions of the Creative Commons Attribution (CC BY) license (http://creativecommons.org/licenses/by/4.0/). 